\title{
Caserne Dossin (Malines). Le parti pris de la clarté et des droits de l'homme
}

Kazerne Dossin : Mémorial, Musée et Centre de Documentation sur

l'Holocauste et les Droits de l'Homme

Kazerne Dossin (Mechelen): A choice for clarity and Human Rights. Kazerne

Dossin: Memorial, Museum and Documentation Center on Holocaust and Human

Rights

Kazerne Dossin (Mechelen): Een keuze voor duidelijkheid en mensenrechten.

Kazerne Dossin: Memoriaal, Museum en Documentatiecentrum over Holocaust

en Mensenrechten

Philippe Mesnard

\section{(2) OpenEdition}

\section{Journals}

Édition électronique

URL : http://journals.openedition.org/temoigner/1163

DOI : $10.4000 /$ temoigner. 1163

ISSN : 2506-6390

Éditeur :

Éditions du Centre d'études et de documentation Mémoire d'Auschwitz, Éditions Kimé

Édition imprimée

Date de publication : 1 mars 2013

Pagination : 110-119

ISBN : 978-2-84174-628-6

ISSN : 2031-4183

Référence électronique

Philippe Mesnard, «Caserne Dossin (Malines). Le parti pris de la clarté et des droits de l'homme »,

Témoigner. Entre histoire et mémoire [En ligne], 115 | 2013, mis en ligne le 01 juin 2015, consulté le 23 octobre 2020. URL : http://journals.openedition.org/temoigner/1163; DOI : https://doi.org/10.4000/ temoigner.1163 


\section{Le parti pris \\ de la clarté et des droits de l'homme}

\section{Kazerne Dossin : Mémorial, Musée et Centre de Documentation sur l'Holocauste et les Droits de l'Homme}

Bâtie dans la ville de Malines (Mechelen en flamand), la Kazerne Dossin a servi aux autorités nazies et aux SS à rassembler les Juifs arrêtés en Belgique avant de les déporter, pour la majorité, vers Auschwitz pour que la plupart y soit gazée et qu'un pourcentage mineur soit astreint au travail forcé avec une espérance de vie de trois mois. Au total, 25 259 déportés, dont 1223 rescapés. Parmi ceuxci, une grande partie était issue d'une immigration récente, souvent venue de l'Est, en général, et de la Pologne, en particulier, pour échapper aux pogroms et à l'antisémitisme, ou à la précarité économique et politique du pays où ils s'étaient installés. C'est dire que quantité de Juifs résidant en Belgique à l'heure du nazisme avaient déjà connu le racisme, les persécutions, la condition de réfugiés, de demandeurs d'asile et d'immigrés. Ancienne caserne, Dossin a été l'équivalent de Westerbork en Hollande, de Drancy en France, de Fossoli en Italie...

Jusqu'en 2012, le musée était installé dans une partie de l'enceinte du bâtiment même. Le 26 novembre de cette même année, a été ouvert un nouvel espace muséogra- phique logé dans un grand cube faisant face à l'ancienne caserne dont une salle seulement est maintenant conservée comme mémorial. Contrairement à la tendance lourde des actuelles scénographies muséales, Herman Van Goethem, promoteur et conservateur de ce musée, n’a pas privilégié les jeux d'ombres et les dispositifs immersifs qui invitent les visiteurs à se plonger, par empathie, dans une ambiance simulée qui les rapprocherait de l'expérience des victimes (et leur procurerait l'illusion rédimante de cette impossible proximité).

Les salles sont lumineuses, hautes de plafond, les informations facilement accessibles et tout à fait intelligibles privilégiant par là même l'aspect didactique de l'économie représentationnelle. Autre pari d'envergure et non sans risque intellectuel brillamment relevé, le déroulement de l'exposition permanente établit constamment des liens entre ce qui a conduit à la Shoah, dans la situation particulière de la Seconde Guerre mondiale, et - sans aucunement diminuer la spécificité de ce génocide - les mécanismes de discrimination et de violence de masse qui ont permis d'autres violences collectives sur des groupes minoritaires ou dominés, généralement victimes de stigmatisation raciale.

L'exposition permanente est répartie sur trois étages thématiquement développés comme suit. D’abord, « La masse », ensuite, « Langoisse », enfin, « La mort ». Le quatrième est dédié aux expositions temporaires et donne aux visiteurs une vue plongeante sur l'ancienne antichambre de la mort.

Philippe Mesnard 


\section{Een keuze \\ voor duidelijkheid en mensenrechten}

\section{Kazerne Dossin: Memoriaal, Museum en Documentatiecentrum over Holocaust en Mensenrechten}

De Kazerne Dossin werd opgericht in de stad Mechelen en heeft de SS en de nazioverheden gediend om de in België gearresteerde Joden te verzamelen alvorens hen te deporteren, voor het merendeel naar Auschwitz. De meesten werden er vergast, een klein percentage werd gedwongen om dwangarbeid uit te voeren, de gemiddelde levensverwachting was drie maanden. In het totaal ging het hier om 25259 gedeporteerden, waar er 1223 van teruggekomen zijn. Een groot deel onder hen kwam uit een recente immigratie, vaak uit het Oosten in het algemeen en Polen in het bijzonder. Dit om aan de pogroms, het antisemitisme of economische of politieke onzekerheid te ontsnappen. Dit betekent dat veel Joden ten tijde van het nazisme in België reeds racisme, vervolgingen en de toestand van vluchtelingen, asielzoekers en immigranten hadden ervaren. De voormalige kazerne Dossin was vergelijkbaar met Westerbork in Nederland, Drancy in Frankrijk, Fossoli in Italië...

Tot 2012 werd het museum ondergebracht in een deel van het gebouw zelf. Op 26 november van hetzelfde jaar opende een nieuwe tentoonstellingsruimte, ondergebracht in een grote kubus met uitzicht op de voormalige kazerne, waarin een ruimte wordt bewaard als gedenkteken. In tegenstelling tot de trend van de huidige scenografie in de musea, heeft Herman Van Goethem als ontwikkelaar en curator er niet voor gekozen de bezoeker te dompelen in een gesimuleerde sfeer die hem dichter bij de ervaring van de slachtoffers zou brengen (en die hem de verlossende illusie zou geven van een onmogelijke nabijheid).

De zalen zijn verlicht, met hoge plafonds, de informatie is bereikbaar en verstaanbaar, waarbij het didactische aspect van de voorstelling de voorkeur krijgt. Een andere geslaagde weddenschap, dat overigens niet zonder intellectueel risico was, is het aanbrengen van de linken die naar de Holocaust hebben geleid, in de bijzondere context van de Tweede Wereldoorlog en - zonder enigszins de specificiteit van deze genocide te verminderen - de mechanismen van de discriminatie en het massageweld die de baan hebben geëffend naar ander collectief geweld op minderheidsgroepen of gedomineerde groepen die meestal het slachtoffer waren van raciale stigmatisering.

De permanente tentoonstelling is verdeeld volgens drie thematische verdiepingen. Eerst de "massa", dan de "angst" en vervolgens de "dood". Op het vierde verdiep kunnen tijdelijke tentoonstellingen ondergebracht worden en hebben de bezoekers een zicht op de wachtkamer van de dood.

\section{Philippe Mesnard}




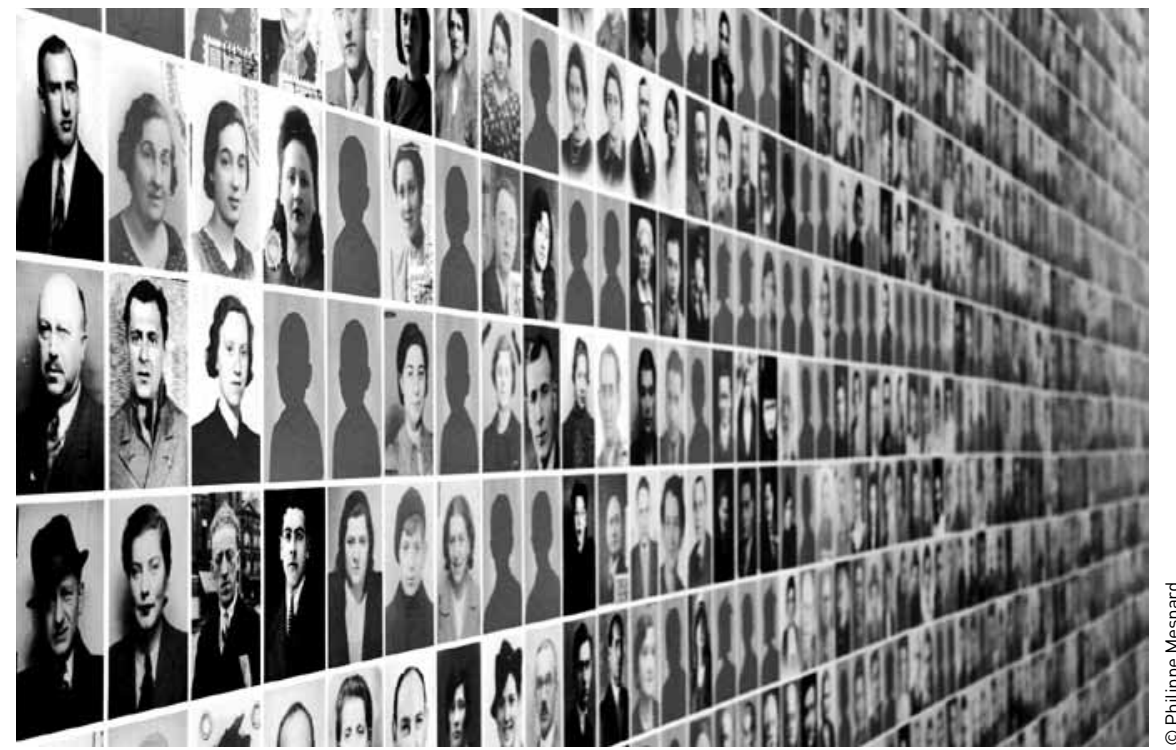

Mur de visages placé dans le hall d'entrée représentant précisément l'ensemble des Juifs déportés de Dossin, soit 24908 Juifs et 351 Tsiganes. Photos couleur : ayant survécu. Photos noir et blanc : assassinés ou morts des suites des conditions du camps. Visages anonymes : mort sans que puisse être identifié leur visage.
Muur van gezichten in de inkomsthal die het geheel van de uit Dossin gedeporteerde Joden uitbeeldt, het gaat om 24908 Joden en 351 Roma en Sinti. In kleur: de overlevenden. In zwart-wit: de vermoordden of degenen die overleden zijn door de kampomstandigheden. Anonieme gezichten: degenen die overleden zijn zonder dat een identificatie mogelijk was.

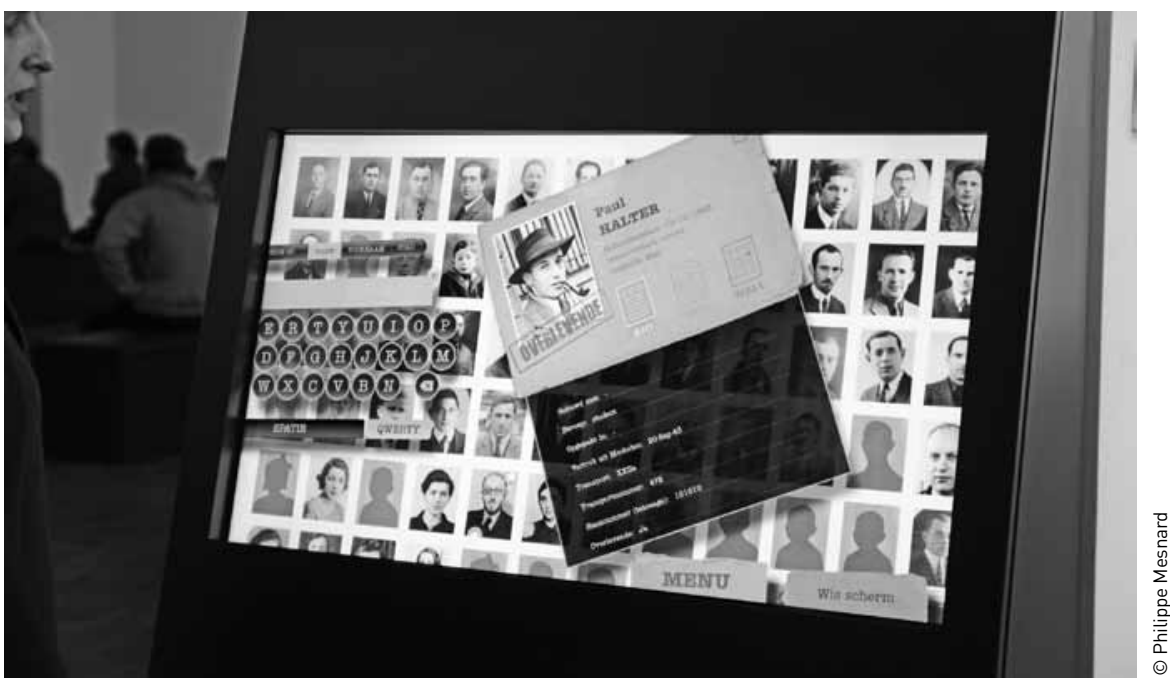

Console interactive.

Interactieve touchscreen. 


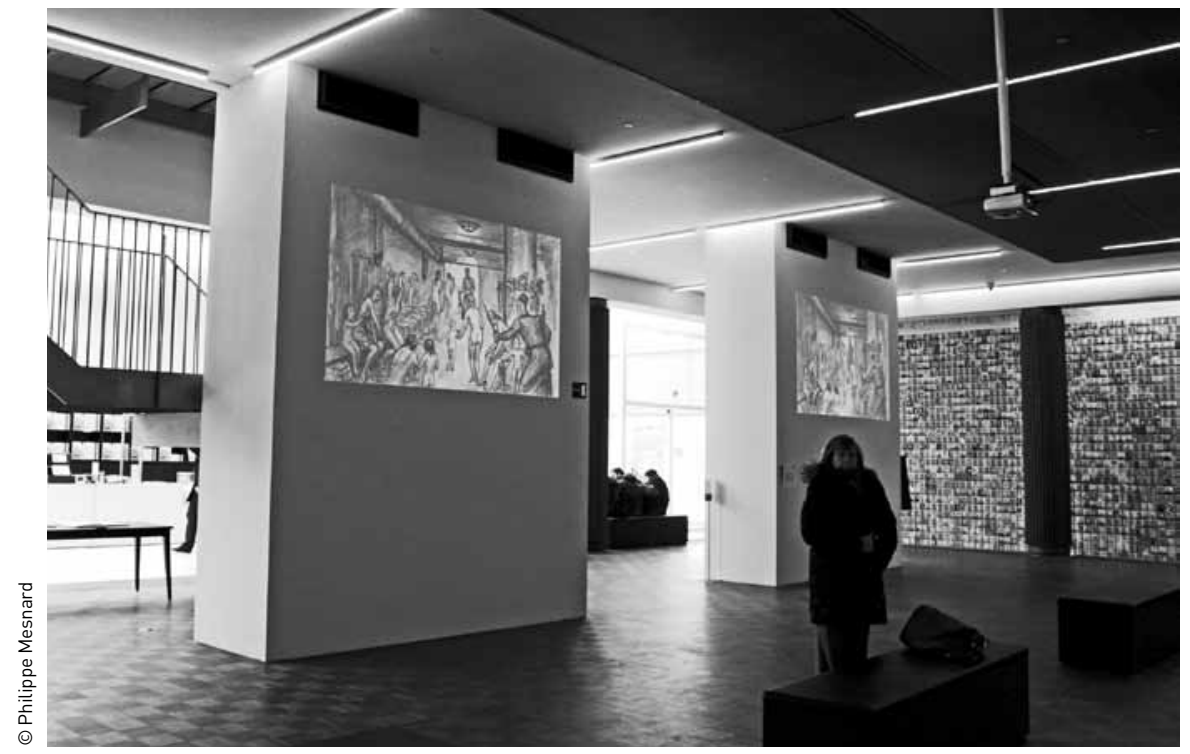

Hall d'entrée, projection d'un film pédagogique, ici, un dessin du Sonderkommando David Olère documentant le passage d'un groupe de Juifs sélectionnés pour la chambre à gaz.
Inkomhal, vertoning van een pedagogisch filmpje. Hier een tekening van de Sonderkommando David Olère, die de doorgang van een groep Joden naar de gaskamer illustreert.

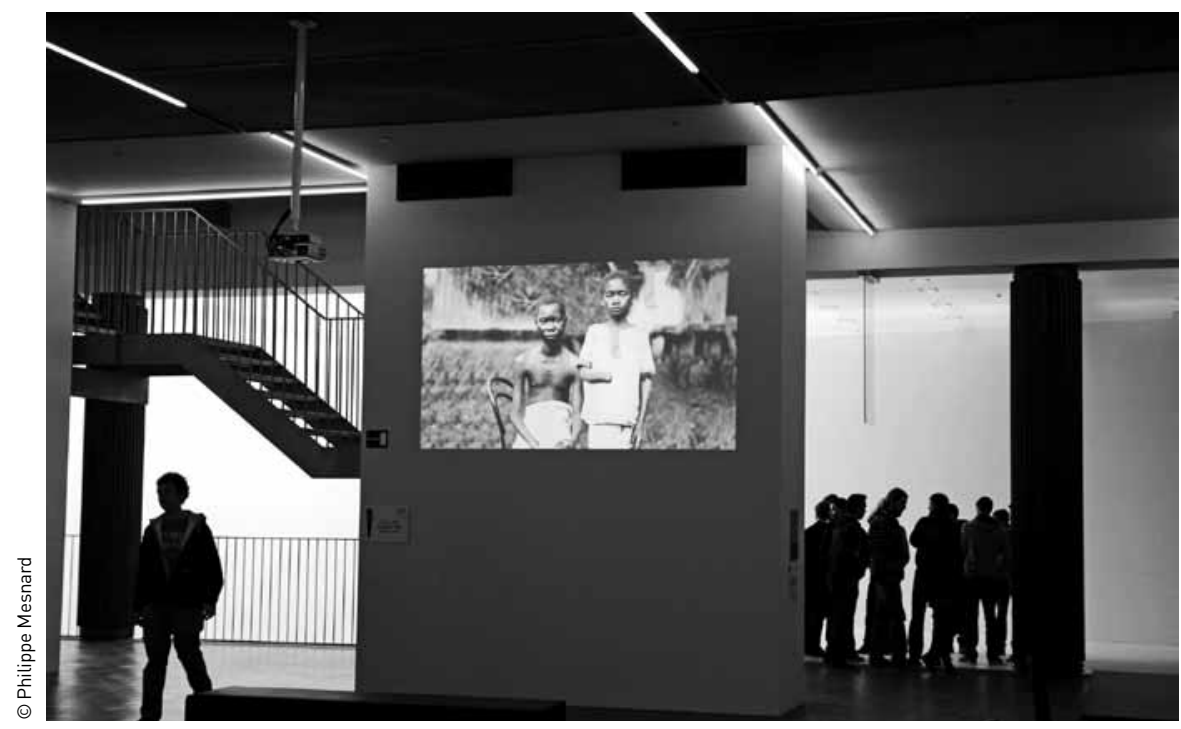

Hall d'entrée, même film, séquence sur les sévices infligés à de jeunes Africains.
Inkomhal, dezelfde film, fragment over geweldplegingen toebedeeld aan jonge Afrikanen. 


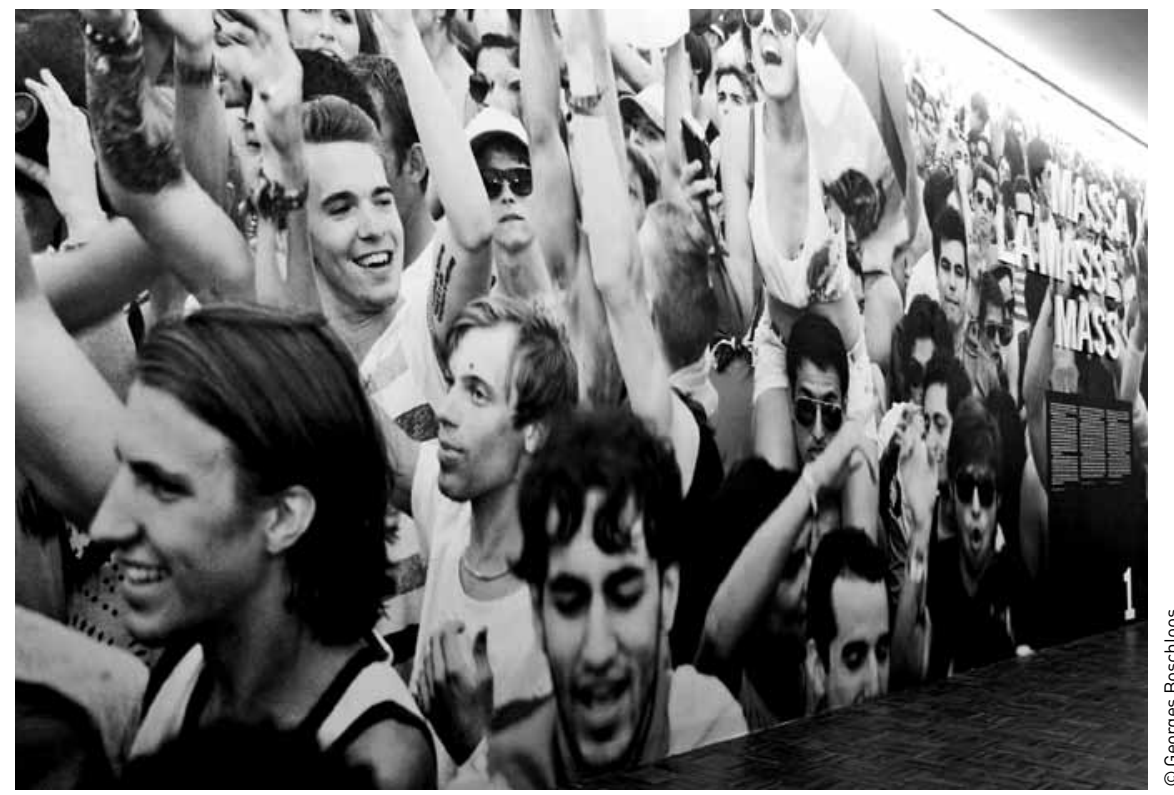

Premier étage de l'exposition permanente.

Eerste verdiep van de permanente tentoonstelling.

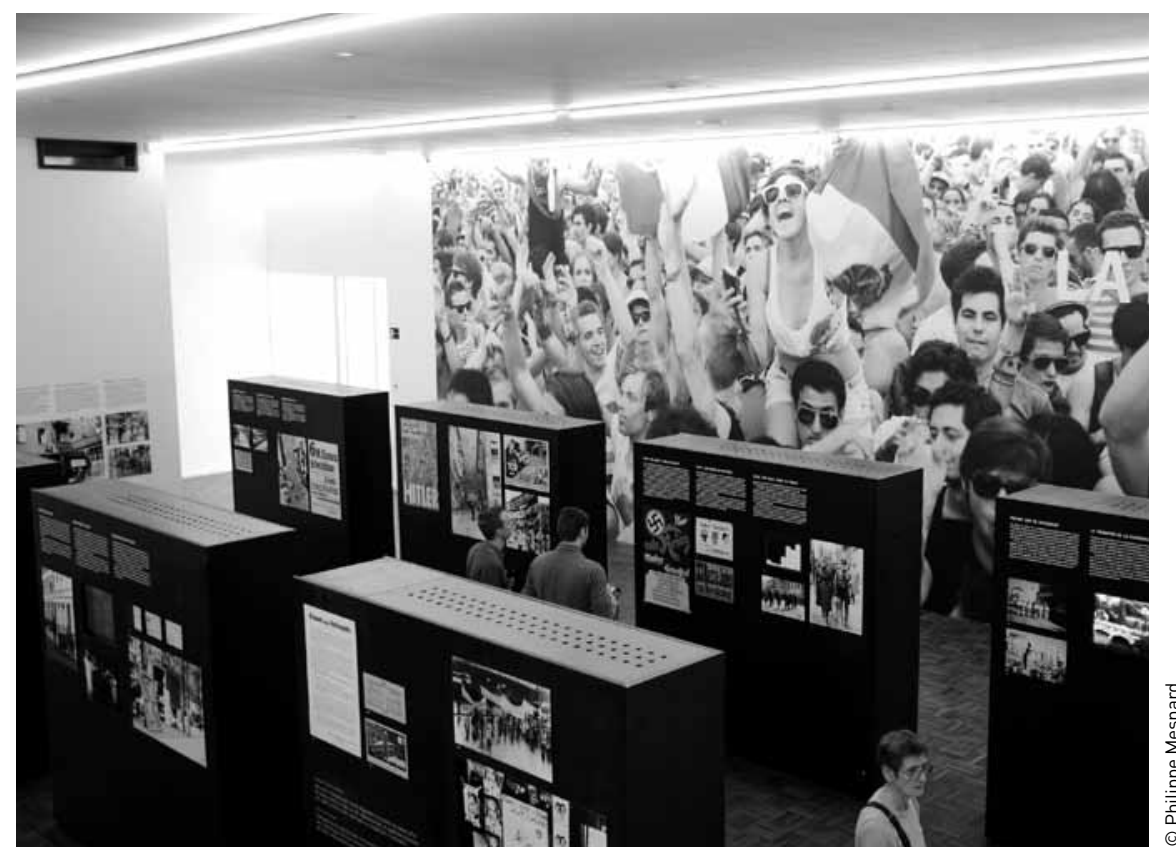



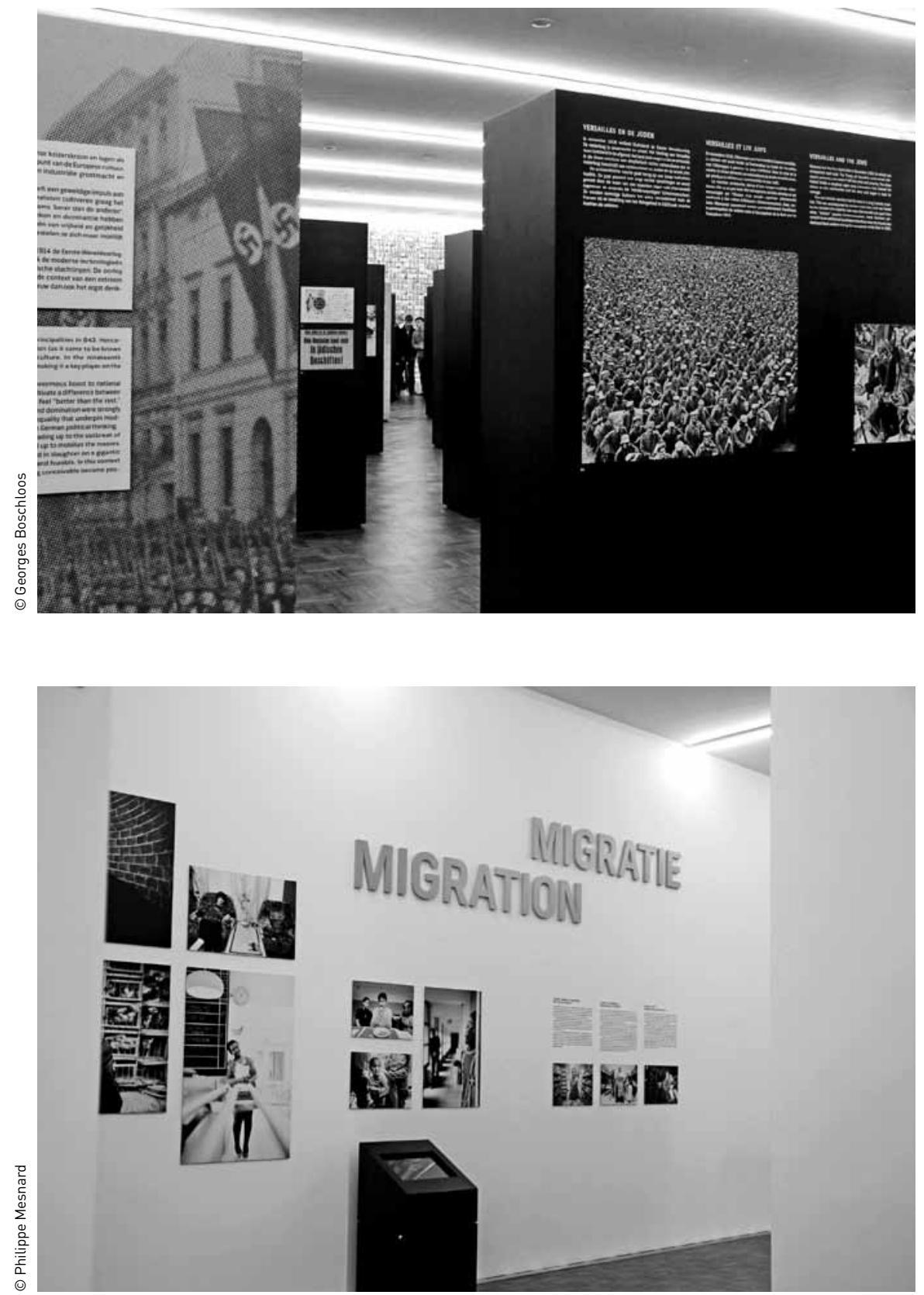

Thématique liée à l'atteinte aux droits de l'homme comme transition, près de l'escalier, entre la masse (1 ${ }^{\mathrm{er}}$ étage) et l'angoisse ( $2^{\mathrm{e}}$ étage).
Thematiek gekoppeld aan de mensenrechten, met aan de trap een overgang van het eerste verdiep (massa) naar het tweede verdiep (angst). 


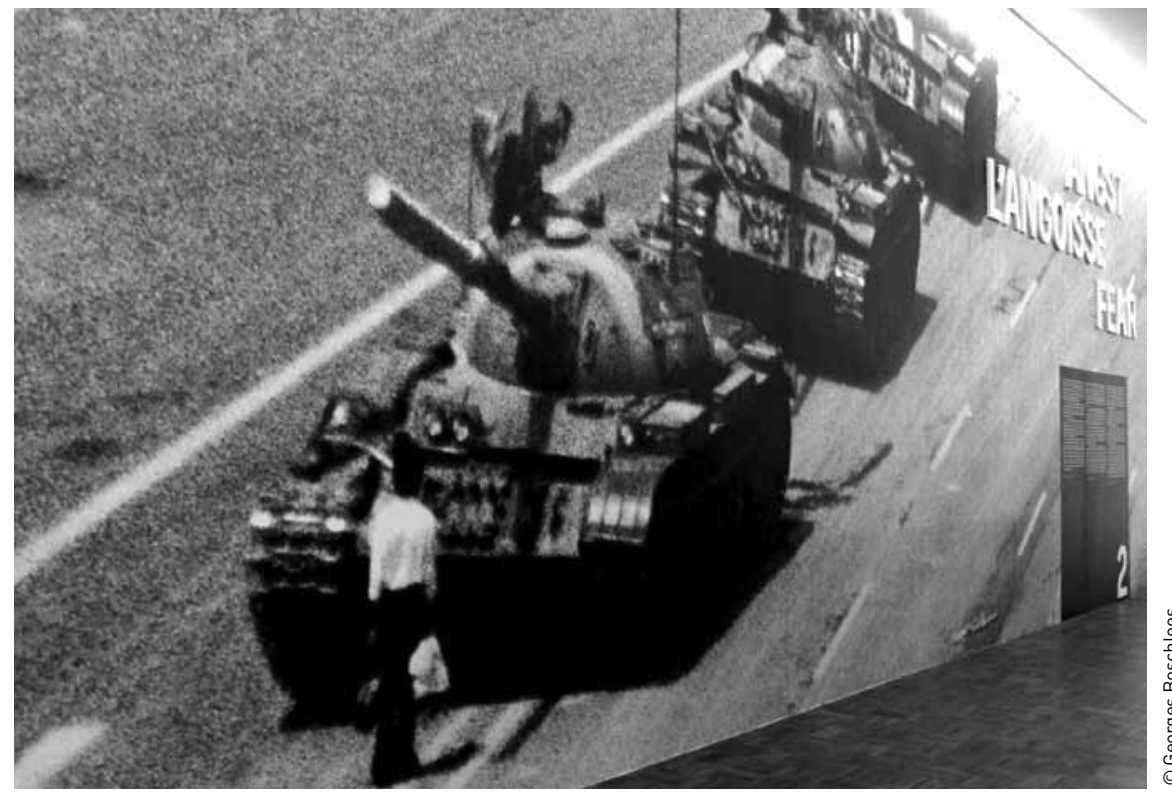

Deuxième étage de l'exposition permanente. Tweede verdieping van de permanente tentoonstelling.

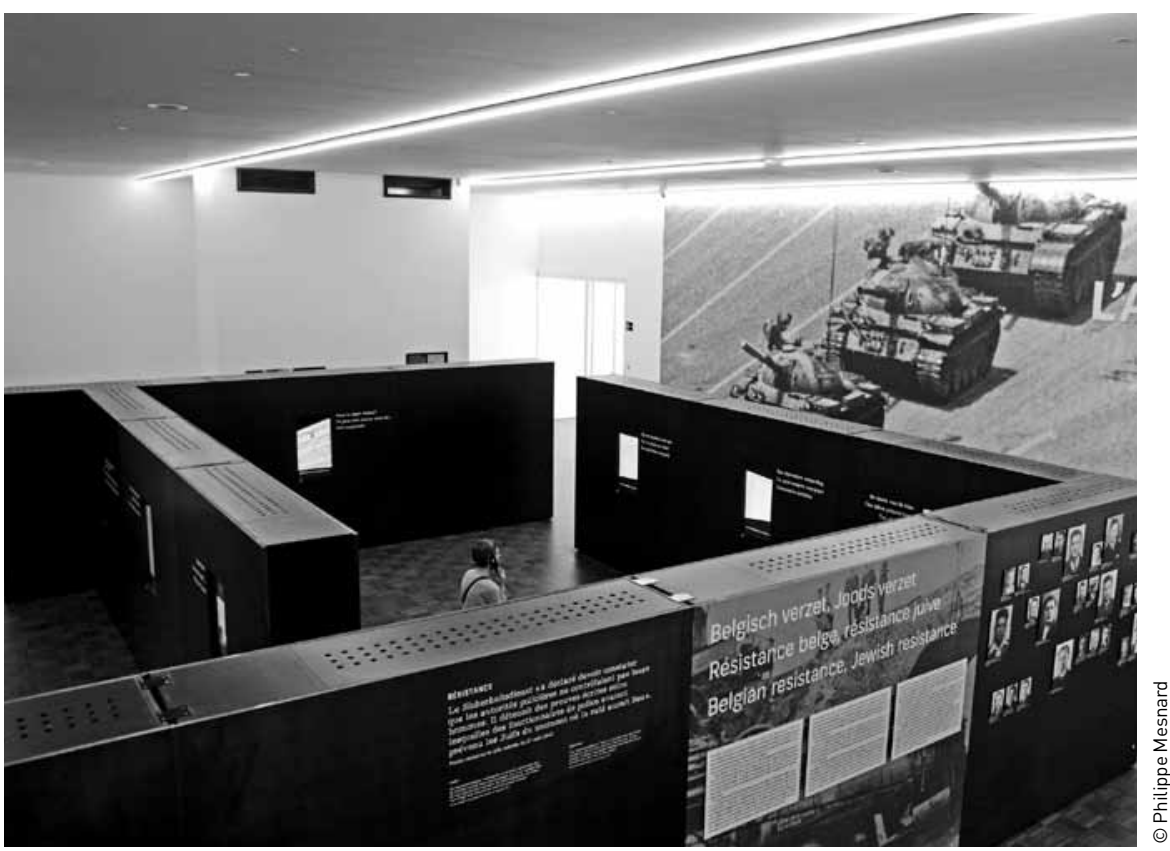



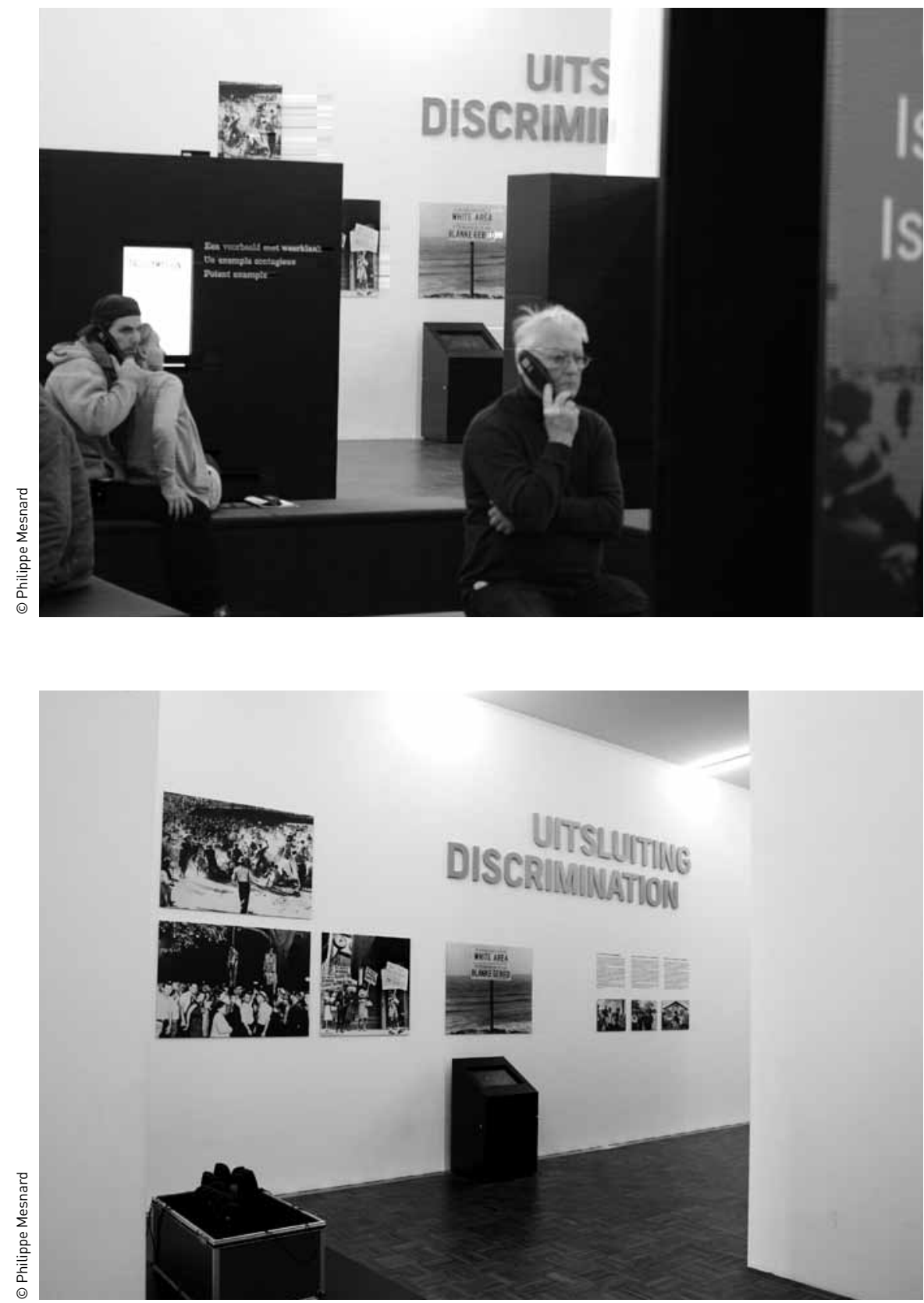

Thématique liée aux droits de l'homme comme transition, près de l'escalier, entre l'angoisse ( $2^{\mathrm{e}}$ étage) et la mort ( $3^{\mathrm{e}}$ étage).
Thematiek gekoppeld aan de mensenrechten, met aan de trap een overgang van de tweede verdieping (angst) naar de derde verdieping (dood). 

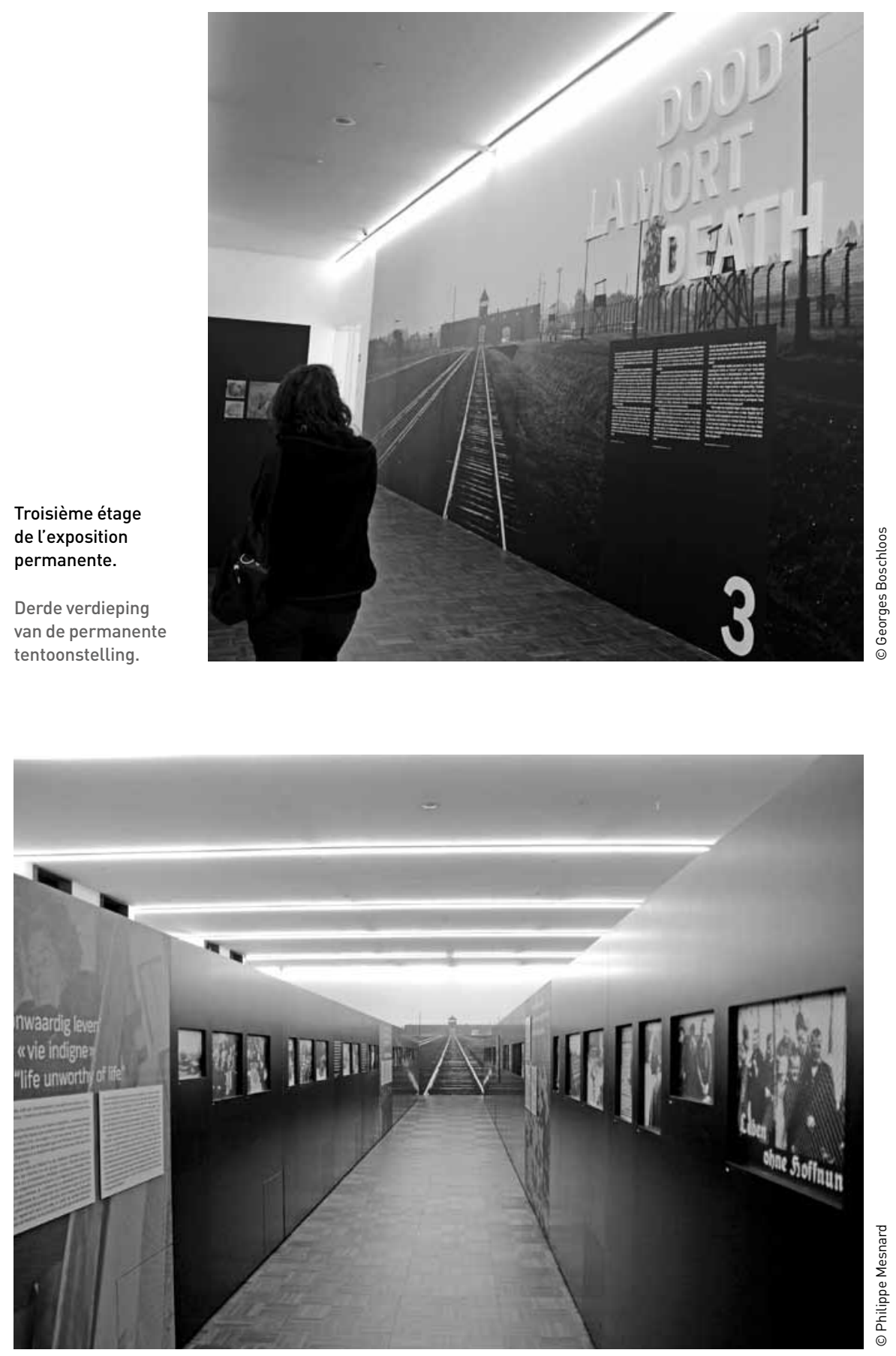


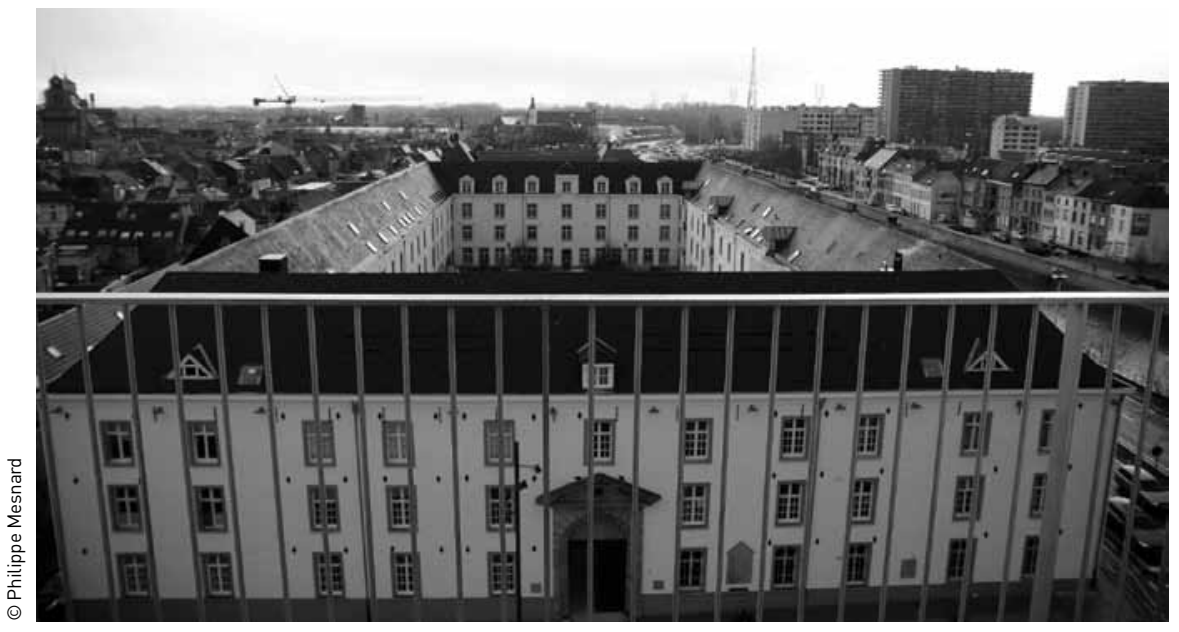

Vue plongeante du quatrième étage du musée Vogelperspectief op de kazerne Dossin vanop sur la caserne Dossin. de vierde verdieping van het museum.

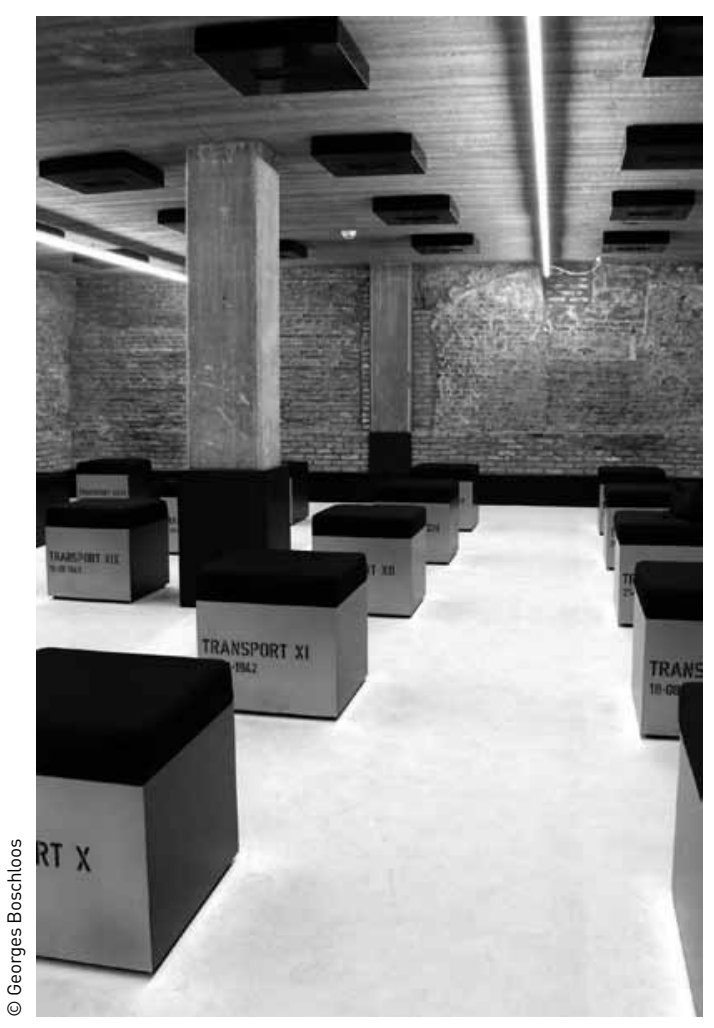

Mémorial dans la caserne Dossin. Chaque stèle représente un des 28 convois de déportation partis de Malines.

Gedenkteken in de feitelijke kazerne. Elke kolom stelt één van de 28 transporten voor die uit Mechelen vertrokken zijn. 